\title{
A simple indicator of correct nasogastric suction tube placement in children and adults
}

The aim of this preliminary study was to determine the validity of a flexible fiberoptic cable inserted into a nasogastric tube in assessing correct gastric placement of the tube in children and adults. The study enrolled 16 patients undergoing surgical procedures ( $\beta$-thalassemic children and 8 patients subjected respectively to open splenectomy and laparoscopic cholecystectomy). A flexible cable of $1.3 \mathrm{~mm}$ diameter, connected with a cold light source, was inserted in a common nasogastric tube and advanced as far as the epigastric area ( $\bullet$ Fig. 1-3), which was fully transilluminated. The stomach was emptied by aspiration with a syringe. The size of the nasogastric tubes varied between 8 and $19 \operatorname{Fr}(2.7-$ $6.3 \mathrm{~mm}$ ).

All of the patients had the epigastric area transilluminated, and the liquid obtained from the nasogastric tube aspiration was of clear yellow color. Moreover, correct positioning of the nasogastric tube was confirmed at the time of operation in all the patients, and no postinsertion complications were recorded.

Preoperative insertion of a flexible fiberoptic cable into a nasogastric tube may be useful in allowing the operator to check that the device is progressing correctly through the esophagus and correctly placed inside the stomach. This instrument also allows preoperative stomach emptying. We believe that this finding deserves consideration as it represents a useful, safe, and cost-effective tool for surgeons. This particular device could also be useful in critically ill patients requiring gastric or enteral feeding, in whom frequent checking of tube placement is needed. Further tests performed on a greater number of patients are needed for a better evaluation of the importance, possible applications, and manageability of this device.

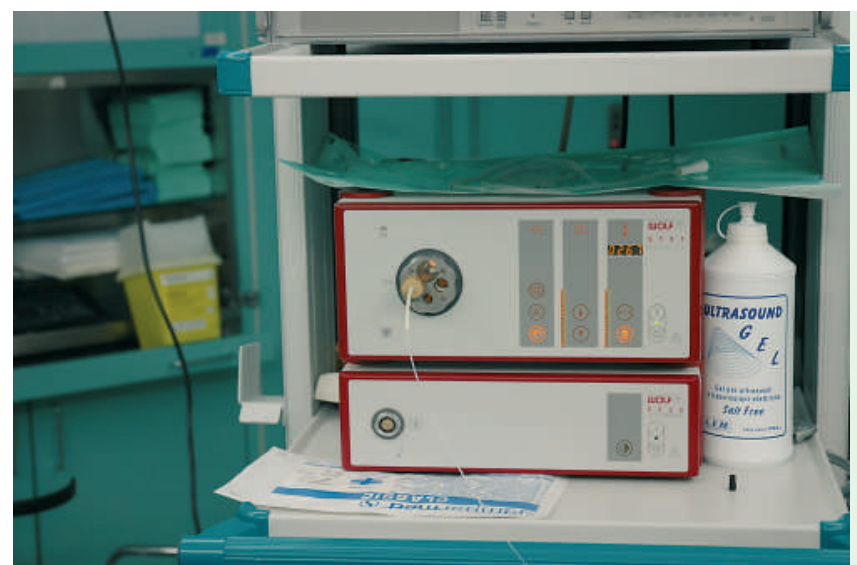

Fig. 1 Fiberoptic cable connected to a cold light source.

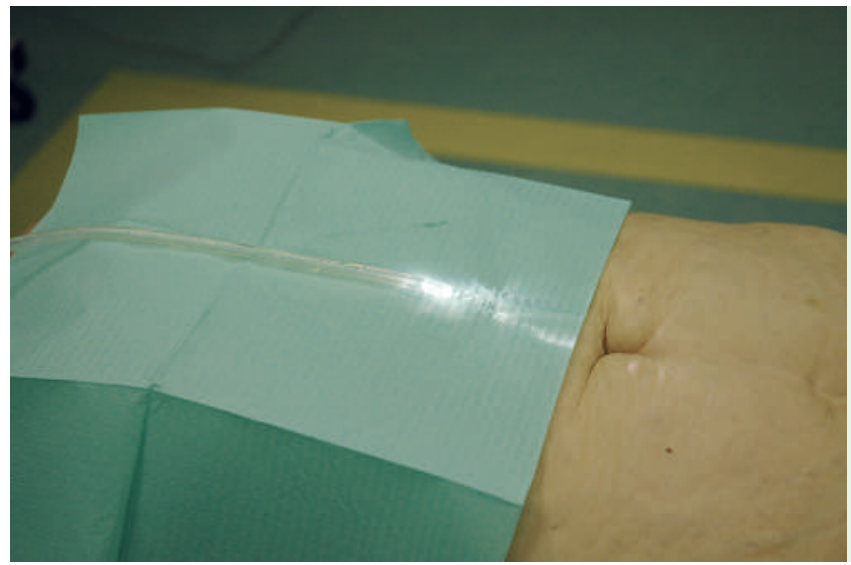

Fig. 2 The flexible fiberoptic cable.

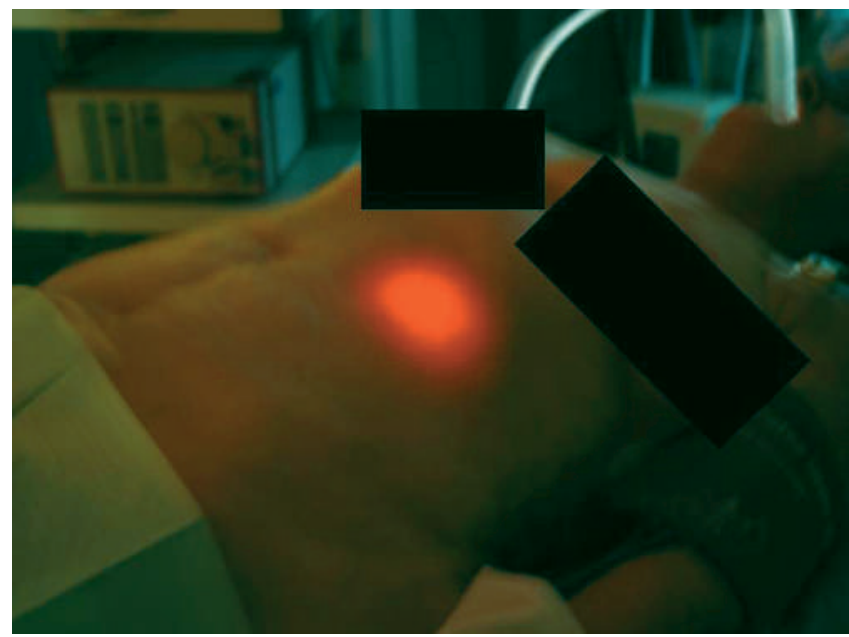

Fig. 3 Transillumination of the upper abdominal wall. 


\section{Acknowledgment}

$\nabla$

This work has been partially funded by a grant from the Italian Ministry of University and Research.

Endoscopy_UCTN_Code_TTT_1AO_2AK
F. Rulli ${ }^{1,2}$, G. Galatà ${ }^{1}$, M. Villa', A. Maura ${ }^{2}$, C. Ridolfi ${ }^{1}$, M. Grande ${ }^{1}$,

A. M. Farinon ${ }^{1}$

1 Department of Surgery, Tor Vergata University of Rome, Italy

2 Unit of Innovative Surgical Technologies (Medical Engineering School), Tor Vergata University of Rome, Italy
Bibliography

DOI 10.1055/s-2007-966613

Endoscopy 2007; 39: E237-E238

(c) Georg Thieme Verlag KG Stuttgart · New York . ISSN 0013-726X

Corresponding author

\section{F. Rulli, MD}

University of Rome "Tor Vergata”

Viale Oxford 81

00133 Roma

Italy

Fax: +39-062-9902976

francesco.rulli@ptvonline.it 